\title{
AEROSOL ACTIVITY AND HYGROSCOPICITY COMBINED WITH LIDAR DATA IN THE URBAN ATMOSPHERE OF ATHENS, GREECE IN THE FRAME OF THE HYGRA_CD CAMPAIGN
}

\author{
Aikaterini Bougiatioti ${ }^{1,2 *}$, Alexandros Papayannis ${ }^{1}$, Stergios Vratolis $^{3}$, Athina Argyrouli ${ }^{1}$, Nikolaos \\ Mihalopoulos $^{4,5}$, Maria Tsagkaraki ${ }^{5}$, Athanasios Nenes ${ }^{2,6}$ and Konstantinos Eleftheriadis ${ }^{3}$ \\ ${ }^{1}$ Laser Remote Sensing Laboratory, National Technical University of Athens, 15780 Athens, GREECE \\ *Email:kbougioti@gmail.com \\ ${ }^{2}$ School of Earth \& Atmospheric Sciences and Chemical \& Biomolecular Engineering, Georgia Institute \\ of Technology, Atlanta 30332, GA, USA \\ ${ }^{3}$ ERL, INRSTES, N.C.S.R. Demokritos, 15310 Agia Paraskevi, Attiki, GREECE \\ ${ }^{4}$ IERSD, National Observatory of Athens, Palaia Penteli, GREECE \\ ${ }^{5}$ ECPL, Department of Chemistry, University of Crete, 71003 Heraklion, GREECE \\ ${ }^{6}$ ICE-HT, Foundation for Research and Technology, Hellas, 26504 Patras, GREECE
}

\begin{abstract}
Measurements of cloud condensation nuclei (CCN) concentrations between $0.2-1.0 \%$ supersaturation and aerosol size distribution were performed at an urban background site of Athens during HygrA-CD. The site is affected by local and long-range transported emissions as portrayed by the external mixing of the particles, as the larger ones appear to be more hygroscopic and more $\mathrm{CCN}$-active than smaller ones. Activation fractions at all supersaturations exhibit a diurnal variability with minimum values around noon, which are considerably lower than unity. This reinforces the conclusion that the aerosol is mostly externally mixed between "fresher", less hygroscopic components with more aged, CCN active constituents.
\end{abstract}

\section{INTRODUCTION}

The international HygrA-CD field campaign took place between 15 May and 22 June, 2014, in the frame of the Initial Training on Atmospheric Remote Sensing (ITARS) project. Hygra-CD brought together different instruments and expertise aiming to enhance our understanding on the impact of aerosols and clouds on weather and climate (http://hygracd.impworks.gr). It was based on the synergy between remote sensing and in-situ instrumentation, making also use of numerical weather prediction and atmospheric modeling.
Aerosol particles, especially the anthropogenic ones, are important components of climate change, via absorption and scattering of incoming radiation [1]. They can also act as $\mathrm{CCN}$ and "indirectly" force climate through modification of cloud radiative properties and precipitation efficiency, according to the Twomey effect [2]. The main physico-chemical principles involved in the transformation ("activation") of $\mathrm{CCN}$ into a cloud droplet involve the effects of curvature and solute on the equilibrium water vapor pressure, represented by the Köhler theory [3]. It constitutes the theoretical basis for linking aerosol to $\mathrm{CCN}$ activity, by determining the characteristic level of ambient water vapor supersaturation $\left(S_{c}\right)$, required for particles to activate into cloud droplets. For a given aerosol particle, $S$ depends on the particle dry size and chemical composition.

Simple representations of solute hygroscopicity in Köhler theory are fitted to a one-parameter model, where the hygroscopicity parameter $(\kappa)$ represents a quantitative measure of aerosol water uptake characteristics and $\mathrm{CCN}$ activity [4]. Typical values of $\kappa$ vary between 0 , for insoluble wettable materials that do not significantly affect water activity via adsorption, $\sim 0.1-0.2$ for oxidized secondary organic aerosol (SOA) and $\sim 0.6$ for pure ammonium sulfate and nitrate.

Continental and marine aerosols tend to cluster around $\kappa \sim 0.3-0.7$, respectively, with a fair amount 
of variability across space and time, depending mainly on the organics mass fraction, relative abundance of ammonium sulfate, as well as particle size [5].

\section{METHODOLOGY}

The measuring site in Athens was located in Demokritos WMO-GAW station $\left(37.995^{\circ} \mathrm{N}\right.$, $23.816^{\circ} \mathrm{E}, 250 \mathrm{~m}$ a.s.1.), at a distance of $\sim 8 \mathrm{~km}$ from the city center. The sampling location was influenced by aerosol particles (PM) emitted from the city under S and NW wind flow regimes. The instrumentation setup consisted of a Droplet Measurement Technologies (DMT) streamwise thermal-gradient $\mathrm{CCN}$ counter [6] and a scanning mobility particle sizer (SMPS) composed of a custom-made differential mobility analyzer and a condensation particle counter (TSI Model 3772) used to measure the dry aerosol size distribution. Throughout the campaign, the instrument was operated at a total flow rate of $0.5 \mathrm{~L} \mathrm{~min}^{-1}$, with a sheath-to-aerosol flow ratio of $10: 1$, and a topbottom column difference, $\Delta \mathrm{T}$ between 4 and 15 $\mathrm{K}$. Concentrations were measured at each supersaturation for $10 \mathrm{~min}$, yielding a CCN spectrum consisting of 5 different supersaturations every $50 \mathrm{~min}$.

To support the aerosol ground measurements the AIAS mobile one-wavelength $(532 \mathrm{~nm})$ elastic backscatter depolarization lidar system [7] was deployed in the field to provide information about the dynamic activity of the Planetary Boundary Layer (PBL) (from $\sim 300 \mathrm{~m}$ above ground level to $1500 \mathrm{~m}$ a.sl.) and to strengthen the link between $\mathrm{CCN}$ activity and cloud formation.

Aerosol activate in the CCNc when $S_{\mathrm{c}}>$ than the instantaneous supersaturation $(S)$, in the $\mathrm{CCNc}$ column. This $S_{\mathrm{c}}$ corresponds to a critical diameter $\left(d_{\mathrm{p}, \mathrm{c})}\right.$ above which all particles activate. These parameters are used to determine the parameter $\kappa$ :

$$
\kappa=\frac{4 \mathrm{~A}^{3}}{27 d_{p, c}^{3} S_{c}^{2}} \text {, where } \mathrm{A}=\left(4 \mathrm{M}_{\mathrm{w}} \sigma_{\mathrm{w}}\right) /\left(\mathrm{RT} \rho_{\mathrm{w}}\right), \mathrm{R} \text { is }
$$

the universal gas constant and $\mathrm{M}_{\mathrm{w}}, \sigma_{\mathrm{w}}$ and $\rho_{\mathrm{w}}$ are the molar mass, surface tension and density, respectively, of water at the average mid-column temperature, $\mathrm{T}$, in the CCNc. The $d_{p, c}$ is obtained by matching the concentration of $\mathrm{CCN}$ activated at a given $S$ with the backwards integrated SMPS number distribution.

\section{RESULTS}

In this paper we focus on the period of 18-22 June 2014. In Figure 1 (upper and lower graphs) we present the available data of the spatio-temporal evolution of the range-corrected aerosol backscattered lidar signal at $532 \mathrm{~nm}$ obtained by AIAS system on 18 and 21 June 2014 from near ground $(0.4 \mathrm{~km})$ to $5 \mathrm{~km}$ height.
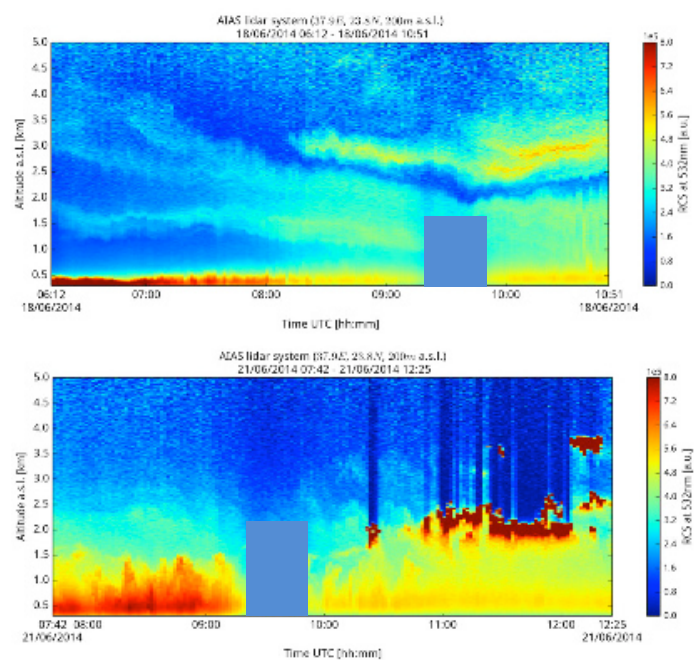

Figure 1: Spatio-temporal evolution of the rangecorrected aerosol backscattered lidar signal at $532 \mathrm{~nm}$ obtained by AIAS system on 18 and 21 June 2014.

In Fig.1 (upper graph) we see that the PBL is limited to $500 \mathrm{~m}$ a.s.l. Taking in account the Athens basin topography, being surrounded by mountains higher than $1 \mathrm{~km}$, this extremely shallow PBL leads to very poor ventilation of the basin and thus to very low air pollution dispersion; therefore high concentrations of aerosols are to be expected near ground. On 21 June (Fig. 1, lower graph) the PBL is significantly higher $(\sim 2 \mathrm{~km})$ and strong convective conditions drive ground aerosols to higher heights leading to their dispersion and dilution, so forming a cloudtopped PBL.

Figure 2 shows the $\mathrm{CCN}$ concentrations measured from 17 to 22 June. As seen by AIAS, the highest concentrations are observed on 18 June, linked to very low PBL heights. As the PBL height is gradually increased during the following days, vertical dispersion leads to concurrent decrease of PM concentrations as well. As expected, CCN concentrations were higher with increasing 
supersaturation. $\mathrm{CCN}$ at ss $>0.6 \%$ were generally similar, showing that most of the hygroscopic particles are activated by this supersaturation. The correlation of increased CCN concentrations with similar trends in $\mathrm{NO}_{2}$ (Fig. 2) is an indication that anthropogenic pollution may also lead to increased $\mathrm{CCN}$ numbers, possibly through atmospheric processes. $\mathrm{CCN}$ activity can be also represented by the activation fraction (AF), which is the ratio between the measured $\mathrm{CCN}$ and the total condensation nuclei $(\mathrm{CN})$, calculated by the integration of the aerosol size distribution.

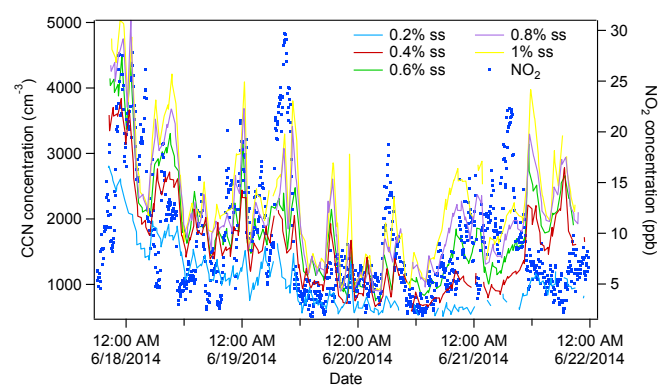

Figure 2: $\mathrm{CCN}$ concentration levels at the measured supersaturations during the measurement period.

Figure 3 shows the calculated AFs at the different measured supersaturations. The average values of the AFs for the five different supersaturations are $0.24 \pm 0.13,0.31 \pm 0.14,0.35 \pm 0.15,0.39 \pm 0.16$ and $0.43 \pm 0.18$, from lowest to highest $S$, respectively.

At the lowest supersaturation the measured $\mathrm{CCN}$ accounted only for a quarter of the total $\mathrm{CN}$, probably because only a minor fraction of the $\mathrm{CN}$ was larger than the activation diameter. It can be seen that generally there is a diurnal variability with ratios having the highest values during nighttime and lower around noon, with values being substantially lower than unity. AFs between 0.6 and $1 \%$ ss do not differ a lot, showing that the $\mathrm{CCN}$-active particles that are present activate at this range of supersaturation.

Also the fact that generally AFs are substantially higher during nighttime denotes the fact that during night the aerosol is more aged and more hygroscopic, compared to the aerosol during day. This might be associated to fresh, local sources such as traffic, emitting principally smaller, nonhygroscopic particles that can form external mixtures and lower the $\mathrm{CCN}$ activity of the sampled aerosol. Similar to our observations, Rose et al. [8] observed at the mega-city
Guangzhou in China, that at the lowest $S$, the maximum activated fraction remained well below one, indicating substantial proportions of externally mixed $\mathrm{CCN}$-inactive particles with much lower hygroscopicity-most likely soot particles.

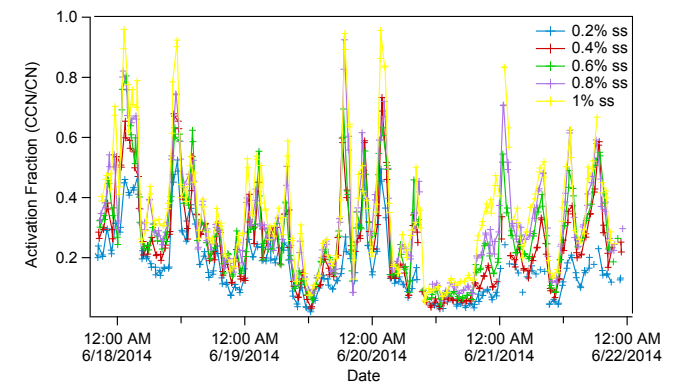

Figure 3: Activation fractions $(\mathrm{CCN} / \mathrm{CN})$ calculated for the different supersaturations.

Finally, the $\kappa$ parameter was calculated for all supersaturations, based on the methodology already presented in the precedent section (Fig. 4). The median values for the five supersaturations were $0.36,0.19,0.13,0.1$ and 0.09 , respectively. It can be seen that $\kappa$ values are higher at the lowest supersaturation and diminish with increasing $S$. This is expected, as the lowest supersaturation corresponds to particles with larger critical diameters. These particles are usually also more hygroscopic, containing higher amounts of inorganic salts. Smaller particles tend to exhibit reduced hygroscopicity.

The observed values are closer to typical values observed for oxidized organics [9] therefore this external mixing causes the overall drop of total hygroscopicity of the sampled aerosol. Once more, the values for the three higher supersaturations are fairly close, indicating the similar chemical composition and mixing state aerosols.

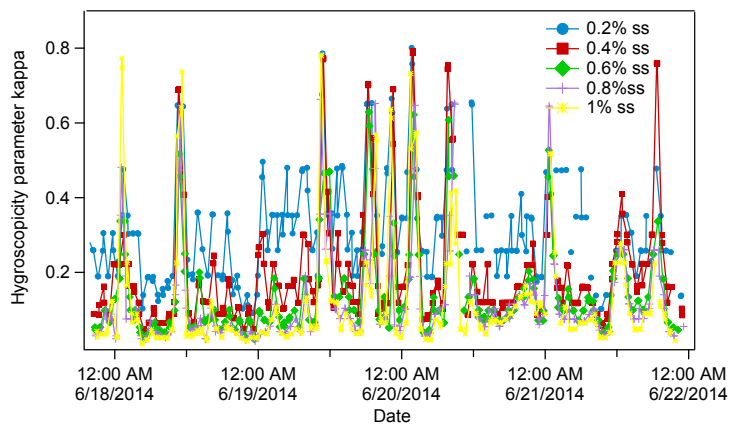

Figure 4: Hygroscopicity parameter, $\kappa$, calculated based on the size distributions for all supersaturations. 
Finally, these values are very close to the measured $\kappa$ values at the same site during summer 2012, where median $\kappa$ for $60 \mathrm{~nm}$ and $80 \mathrm{~nm}$ particles was 0.29 and 0.43 , respectively. This reinforces the conclusion that in this environment there are mostly smaller, less hygroscopic particles present. Our future plans include implementing ISORROPIA II to infer the PM chemical properties aloft ( $\sim 500 \mathrm{~m}$ asl.) [10] and compare them with those obtained at ground level.

\section{CONCLUSIONS}

In this paper we presented the combination of $\mathrm{CCN}$ and lidar measurements which were conducted during HygrA-CD in 2014. During the first days of the CCN measurements the highest concentrations were observed, verified by the structure of the PBL seen by the lidar. This extremely shallow PBL, characterized by poor ventilation and limited dispersion, led to high $\mathrm{CCN}$ concentrations. With the increase of the PBL height on the following days, the $\mathrm{CCN}$ concentrations decreased. AFs exhibited diurnal variability with higher values during nighttime, which remained well below unity during daytime, probably because of external mixing with nonhygroscopic components. Finally, $\kappa$ was calculated for all supersaturations, having lower values with increasing supersaturation. As lower supersaturation values are characterized by larger critical diameters, this means that larger particles are more $\mathrm{CCN}$-active. As supersaturation increases, there is a decrease in critical diameter, which means that smaller particles start to activate, as well. $\kappa$-values at the lowest supersaturation are close to values observed for continental aerosol, while those of the smaller particles are more representative for organic aerosol.

\section{ACKNOWLEDGEMENTS}

$\mathrm{KB}$, AP were supported by the MACAVE research project which is implemented within the framework of the action Supporting of Postdoctoral Researchers of the Operational Program Education and Lifelong Learning (action's beneficiary: General Secretariat for Research and Technology), and is co-financed by the European Social Fund (ESF) and the Greek State. The work of AA was supported by the EU's $7^{\text {th }}$ Framework Programme (FP7/2007-2013) for
Research, Technological Development and Demonstration under grant agreements no 289923 (MC ITN-ITARS). SV and KE acknowledge EnTeC FP7-REGPOT-2012-2013-1, no 316173.

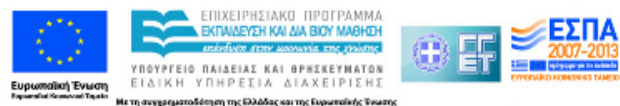

\section{REFERENCES}

[1] Intergovernmental Panel on Climate Change: Climate Change 2013: Synthesis Report, 2013.

[2] Twomey, S., 1977: The influence of pollution on the shortwave albedo of clouds, J. Atmos. Sci., 34, 1149-1152.

[3] Köhler, H., 1936: The nucleus in the growth of hygroscopic droplets, T. Faraday Soc., 32, 1152.

[4] Petters, M. D. and S.M. Kreidenweis, 2007: A single parameter representation of hygroscopic growth and cloud condensation nucleus activity, Atmos. Chem. Phys., 7, 1961-1971.

[5] Bougiatioti A., et al., 2011: Size-resolved CCN distributions and activation kinetics of aged continental and marine aerosol, Atmos. Chem. Phys., 11, 8791-8808.

[6] Roberts, G. and A. Nenes, 2005: A continuous-flow streamwise thermal gradient $\mathrm{CCN}$ chamber for atmospheric measurements, Aerosol Sci. Tech., 39, 206-221.

[7] A. Papayannis, et al., 2012: ARIADNE: The Greek Lidar Network, Proc. $26^{\text {th }}$ ILRC, Porto Heli, Greece, 349-352.

[8] Rose, D., et al., 2010: Cloud condensation nuclei in polluted air and biomass burning smoke near the megacity Guangzhou, ChinaPart 1: Size-resolved measurements and implications for the modeling of aerosol particle hygroscopicity and CCN activity, Atmos. Chem. Phys., 10, 3365-3383.

[9] Engelhart, G. J., et al., 2011: CCN Activity of Isoprene Secondary Organic Aerosol, $J$. Geophys. Res., 116, D02207, doi:10.1029/2010JD014706.

[10] Mamouri, R.E., et al., 2012: Multiwavelength Raman lidar, sun photometric and aircraft measurements in combination with inversion models for the estimation of the aerosol optical and physico-chemical properties over Athens, Greece, Atmos. Meas. Tech., 5, 1793-1808. 